\title{
DESENVOLVIMENTO DE JOGOS DIDÁTICOS PARA O ENSINO DE QUÍMICA: UMA EXPERIÊNCIA DAS OFICINAS DE PRÁTICAS PEDAGÓGICAS
}

\author{
DEVELOPMENT OF DIDACTIC GAMES FOR TEACHING CHEMISTRY: AN EXPERIENCE OF \\ PEDAGOGICAL PRACTICES WORKSHOPS
}

DESARROLLO DE JUEGOS DIDÁCTICOS PARA LA ENSEÑANZA DE LA QUÍMICA: UNA EXPERIENCIA DE TALLERES DE PRÁCTICAS PEDAGÓGICAS

\section{Sally Katiuce Moccelini \\ iD 9 \\ Doutora em Química (UFSC) \\ Graduanda em Licenciatura em \\ Química (IFMT) \\ sallykm@gmail.com}

\section{Douglas Gonçalves Sete (iD) 9}

Mestre em Ensino de Ciências Exatas (UNIVATES)

Professor do IFMT

douglas.sete@pdl.ifmt.edu.br

\begin{abstract}
Resumo
Esta pesquisa visa verificar a importância do desenvolvimento de jogos didáticos para os acadêmicos do curso de Licenciatura em Química nas disciplinas de Oficinas de Práticas Pedagógicas e sua contribuição para a prática docente. Nestas disciplinas os licenciandos são os autores dos materiais didáticos, aprendendo a planejar aulas com a utilização dos mesmos, buscando harmonizar teoria e prática de forma contextualizada. Esta é uma pesquisa qualitativa e descritiva realizada através de um questionário respondido por estudantes do curso de Licenciatura em Química. Os resultados são referentes a um tempo e contexto específicos e sugerem que esta estratégia é eficaz para a formação profissional dos licenciandos que, numa dinâmica de ação e reflexão, vão aprendendo a serem autores de suas propostas de trabalho, produzindo materiais didáticos e ampliando conhecimentos ao mesmo tempo que vivenciam desde o início do curso a experiência do ensinar.

Palavras-chave: Jogos Didáticos. Ensino de Química. Formação Docente.
\end{abstract}

Recebido em: 21 de abril de 2021 . Aprovado em: 2 de agosto de 2021.

Como citar esse artigo (ABNT):

MOCCELINI, Sally Katiuce; SETE, Douglas Gonçalves. Desenvolvimento de jogos didáticos para o ensino de química: uma experiência das oficinas de práticas pedagógicas. Revista Prática Docente, v. 6, n. 2, e063, 2021. http://doi.org/10.23926/RPD.2021.v6.n2.e063.id1141 


\section{Abstract}

This research aims to verify the importance of the development of didactic games for the students of Degree in Chemistry in the Pedagogical Practices Workshops courses and their contribution to the teaching practice. In these courses, the undergraduates are the authors of the teaching materials, learning to plan classes with the use of them, seeking to harmonize theory and practice in a contextualized way. This is a qualitative and descriptive research carried out through a questionnaire answered by students in the Chemistry Degree course. The results refer to a specific time and context and suggest that this strategy is effective for the professional training of the students, who, in a dynamic of action and reflection, learn how to be the authors of their work proposal, producing didactic materials and expanding their knowledge at the same time as they experience teaching since the beginning of the course.

Keywords: Educational Games. Chemistry Teaching. Teacher Education.

\section{Resumen}

Esta investigación tiene como objetivo verificar la importancia del desarrollo de juegos didácticos para los estudiantes de la Licenciatura en Química en los Talleres de Prácticas Pedagógicas y su contribución a la práctica docente. En estas asignaturas los estudiantes de pregrado son los autores de los materiales didácticos aprendiendo a planificar las clases con el uso de los mismos, buscando armonizar la teoría y la práctica de forma contextualizada. Se trata de una investigación cualitativa y descriptiva realizada a través de un cuestionario respondido por los estudiantes de la Licenciatura en Química. Los resultados se refieren a un momento y contexto específicos y sugieren que esta estrategia es efectiva para la formación profesional del egresado que, en una dinámica de acción y reflexión, aprende a ser el autor de su propuesta de trabajo, produciendo materiales didácticos y ampliando conocimientos mientras experimenta la experiencia docente desde el inicio del curso.

Palabras clave: Juegos Educacionales. Enseñanza de la Química. Educación del Profesorado. 


\section{INTRODUÇÃo}

Segundo os parâmetros curriculares nacionais para o ensino médio (BRASIL, 2000) há uma necessidade de se adotar métodos de aprendizagem ativos e interativos. O processo de aprendizagem é complexo e a escola e o professor podem criar situações nas quais os estudantes são instigados a participar e questionar, incrementando atividades coletivas e desenvolvendo atividades lúdicas onde os estudantes devem se sentir desafiados não somente pelos outros participantes, mas pelo jogo do conhecimento.

Jogos são elementos valiosos na apropriação de conhecimento permitindo o desenvolvimento de competências em comunicação, relacionamento humano, trabalho em equipe, liderança e competição num âmbito formativo. Nesse contexto, o professor pode ampliar seu conhecimento em técnicas ativas de ensino como a utilização de jogos didáticos para estimular os estudantes a se expressarem, através do lúdico e da participação, com os conteúdos escolares (BRASIL, 2002).

Contudo, jogos didáticos devem promover a aprendizagem de conceitos; precisa ser uma atividade planejada e orientada pelo professor. Por isso, essas atividades devem estar relacionadas aos conteúdos, organizadas com regras, num equilíbrio entre as funções lúdica e educativa. Desse modo, os materiais didáticos lúdicos podem ser usados como recurso didático. No caso da Química para o ensino médio são aconselhados os jogos intelectuais que estimulam as habilidades cognitivas e facilitam a interiorização de conteúdos muitas vezes abstratos para os estudantes (CUNHA, 2012).

Nessa tendência de buscar a melhoria no processo de ensino e aprendizagem nas aulas de Química do ensino médio, é importante para o licenciando em Química aprender a elaborar jogos didáticos para o aprendizado de conceitos e, preferencialmente, relacionando os conteúdos com a vida quotidiana. Aprender a planejar bem as aulas com os jogos didáticos para que proporcionem a construção de conhecimentos.

A educação e o ensino são dinâmicos, pois fazem parte do contexto social que é dinâmico. Portanto, o professor precisa estar sempre se atualizando. Inovações pedagógicas geram inquietações (HAYDT, 1995), mas o professor deve planejar e aplicar as aulas com criatividade, contextualizadas, com a inserção de atividades lúdicas, e no caso do ensino de Química, usar da experimentação para associar de forma harmoniosa a teoria e a prática. É necessário mostrar aos estudantes o quanto os fenômenos químicos estão próximos do seu 
quotidiano e da sua realidade, que processos químicos são realizados quando alguém se alimenta, respira ou pensa (SOUZA, 2015).

Quando um novo conhecimento se relaciona de maneira não arbitrária e substantiva à estrutura cognitiva do aprendiz podemos dizer que houve uma aprendizagem significativa. É na direção desta aprendizagem que o significado lógico do material de aprendizagem se transforma em significado psicológico para o sujeito, através de algum conceito ou proposição que já lhe é significativo e adequado para interagir com a nova informação. Desta relação surgem os significados dos materiais potencialmente significativos e o conhecimento prévio se remodela pela aquisição de novos significados (MOREIRA, 2011).

As oficinas pedagógicas são caracterizadas pela integração entre pressupostos teóricos e práticas (PAVIANI; FONTANA, 2009). Com isso, todos têm a oportunidade de explorar, jogar e ver o material lúdico durante a realização das Oficinas de Práticas Pedagógicas do curso de Licenciatura em Química. Os materiais produzidos por cada estudante, ou grupos de estudantes, devem ser apresentados aos demais associados a um determinado conteúdo dentro de uma aula, numa construção coletiva de saberes e de reflexões críticas (CUNHA, 2012; OLIVEIRA et al., 2007).

Tudo isso é importante para o futuro docente desenvolver bem o seu trabalho, especialmente nas escolas públicas que possuem menos investimentos. Nesses locais, os professores podem colocar em prática toda sua criatividade utilizando materiais alternativos e de baixo custo no desenvolvimento de materiais didáticos lúdicos para aulas mais atraentes e interativas, favorecendo a construção de conhecimentos.

Com base nesse contexto, o objetivo dessa pesquisa é verificar a importância do desenvolvimento de jogos didáticos para o ensino de Química nas Oficinas de Práticas Pedagógicas do curso de Licenciatura em Química para os estudantes do curso e sua contribuição para a prática docente.

\section{REFERENCIAL TEÓRICO}

A prática de ensino é fundamental para a formação do professor de Química. É por meio dela que os estudantes desenvolvem competências e habilidades, possibilitando o exercício da docência. Considerando os parâmetros teóricos disciplinares de Química e da Ciência da Educação, realiza ações educativas com criatividade e inovação (SOUZA, 2015). O professor em formação deve desenvolver a habilidade de saber usar adequadamente as técnicas educacionais conforme as diversas e diferentes situações em que o ensino ocorre, o que 
necessariamente implica a criação de novas técnicas em um processo inovador. (PIMENTA; LIMA, 2006).

Segundo Souza (2015), o processo educativo é interativo, e, portanto, social. Nesta interação, os agentes que participam do processo, transmitem e assimilam conhecimentos, trocam ideias, expressam opiniões, compartilham experiências, manifestam suas formas de ver e idealizar o mundo e difundem os valores que orientam suas vidas. O professor pode incentivar a participação do aluno no processo ensino-aprendizagem e na dinâmica de sala de aula com ações, como por exemplo: atividades que envolvam uma situação-problema e mobilizem os esquemas cognitivos de natureza operativa dos estudantes; atividades de expressão oral, nas quais o aluno possa ouvir e fazer-se ouvir; jogos e trabalhos em equipe estimulam o relacionamento entre os alunos e aumentam a integração da classe.

Jogos didáticos são instrumentos motivadores para desenvolver nos estudantes a capacidade de tomar decisões, desde que ocorra uma atividade de reflexão. Mas o professor deve levar em conta os aspectos negativos que podem ocorrer, tais como, a competição exagerada e o desvio da atenção que pode deixar em segundo plano o objetivo pedagógico (SOUZA, 2015). Essas atividades lúdicas podem ser também uma ferramenta para identificar dificuldades enfrentadas pelos estudantes, uma vez que possibilitam experiências e discussões entre eles e seus professores, permitindo uma maior interação entre ambos (ROCHA et al., 2011).

Além disso, segundo Soares (2016), há alguns aspectos que podem ser considerados em uma aplicação didática: o estudante deve ter consciência que o jogo utilizado em sala de aula é educativo e servirá para se discutir um conceito, levando a uma responsabilidade e comprometimento, do professor e do aluno, com a atividade a ser realizada; o aluno deve ser livre para escolher se quer ou não jogar em sala de aula. A estratégia passa a ser um material didático comum se for de forma obrigatória. Jogos só devem ser usados visando uma aprendizagem clara e específica. O professor deve usar sua criatividade para criar seus próprios jogos, conforme seus objetivos de ensino e aprendizagem (SOUZA, 2015). Neste sentido, o professor assume um papel de pesquisador da realidade de sua escola, do interesse e dos conhecimentos prévios de seus alunos, de modo que suas análises orientem as propostas para o ensino de Química (NEVES et al., 2017). O jogo deve provocar nos estudantes novos interesses pelo conteúdo científico, e não pelo aspecto divertido em si. O professor não pode se tornar refém do aspecto lúdico ou de qualquer outro recurso utilizado na sala de aula. Os professores 
devem fundamentar suas práticas lúdicas evitando que as aulas de química sejam esvaziadas de conceitos científicos (MESSEDER NETO; MORADILLO, 2016).

Ademais, um jogo pode ser uma possibilidade de promover a mediação entre professor/estudante e conteúdo/produção de conhecimento. Portanto, a confecção e o uso de jogos didáticos podem ser considerados uma alternativa viável e interessante para o ensino de Química (OLIVEIRA et al., 2018).

Quando nas disciplinas de Oficinas de Práticas Pedagógicas os licenciandos aprendem a desenvolver materiais didáticos, eles devem utilizar os conhecimentos que já aprenderam nas disciplinas anteriores, tanto as voltadas aos conteúdos de Química como aquelas voltadas à educação. Além disso, a construção de um jogo didático é baseada em conhecimentos teóricos do conteúdo que se quer ensinar sem esquecer-se de pensar em como os estudantes aprendem, contextualizando e dando significado ao que se quer ensinar; a prática docente deve integrar os estudantes ao processo de ensino e aprendizagem.

Em uma breve pesquisa em repositórios da web podemos constatar a utilização, ou construção e aplicação de diversos jogos didáticos no ensino de Química. Almeida et al. (2016) relatam a elaboração de um jogo da memória (Memória Balanceada) para o ensino de balanceamento de reações químicas. Este jogo foi desenvolvido durante a disciplina Oficina de Prática Pedagógica de Química Geral do IF Goiano - campus Urutaí. As autoras consideram que a oficina contribui para a formação inicial de professores pois possibilita aprender sobre a prática pedagógica, preparando para os desafios e deveres da realidade das salas de aula.

Nos anais dos Encontros Nacionais de Jogos e Atividades Lúdicas no Ensino de Química são apresentados diversos trabalhos sobre jogos didáticos. O trabalho de Vieira e colaboradores (2014) apresentou o Uno Químico para abordar conteúdos de Química Inorgânica, trabalho desenvolvido na Prática Pedagógica Integrada no IF Farroupilha. Os autores destacam que o jogo é uma ferramenta de ensino dinâmica e positiva diante da falta de infraestrutura das escolas desenvolvendo habilidades.

Pinheiro e Soares (2020) relatam o jogo Mega Senha da Química o qual permite que os conteúdos curriculares possam ser incorporados de forma a relacionar nomenclaturas, conceitos e contexto. Foi um jogo desenvolvido durante a disciplina Oficina Pedagógica II com o qual foi possível instigar nos alunos um compromisso e responsabilidade lúdicos de forma a fazer parte da atuação profissional dos licenciandos. Com esta experiência, despertaram o pensamento 
crítico nos licenciandos levando-os a refletir mais sobre a relação entre conceito e contexto e ainda sanar dúvidas relacionadas ao conhecimento químico.

Evaristo e Coautores (2020) desenvolveram o jogo The Wall Chemistry Game para o ensino dos fatores que influenciam a velocidade das reações químicas. O desenvolvimento do trabalho ocorreu em duas disciplinas de formação docente de um curso de Licenciatura em Química com o objetivo de introduzir uma atividade lúdica no ensino de cinética química em uma dinâmica interativa entre duplas. Os autores acreditam que o material pode enriquecer uma sequência de aulas fomentando o aprendizado dos estudantes e, também, auxiliar na formação profissional com grande potencial para a construção de atividades lúdicas e na capacidade de avaliar suas potencialidades e limitações.

Jesus et al. (2016), abordam o desenvolvimento de um material didático na forma de revista de passatempos químicos produzido por acadêmicos do curso de Licenciatura em Química do Instituto Federal de Educação, Ciência e Tecnologia do Espírito Santo - campus Vila Velha, durante a disciplina de Estágio Supervisionado. O trabalho teve como objetivo contribuir para a formação docente estimulando a vivência em práticas pedagógicas inovadoras. A experiência possibilitou aos licenciandos a reflexão sobre a necessidade de buscar novos meios que promovam uma aprendizagem mais contextualizada e próxima da realidade dos alunos. Ademais, estimulou a criatividade e a superação de desafios em planejar e produzir um material didático totalmente diferente do que estavam acostumados e com o uso de novas tecnologias. Os licenciandos foram inseridos em aspectos da rotina docente, como planejamento e execução de atividades.

Com base nesse cenário, podemos ponderar que o desenvolvimento de jogos didáticos no curso de Licenciatura em Química é uma ferramenta inovadora para a formação profissional docente. A partir das experiências vividas os licenciandos podem demonstrar o seu potencial em planejar e executar aulas com jogos didáticos exercendo sua criatividade, apoiados nos conhecimentos teóricos e de forma contextualizada e desenvolvendo seu pensamento crítico e reflexivo.

\section{Procedimentos do MÉtodo}

O curso de Licenciatura em Química do IFMT Primavera do Leste iniciou em 2017 e apresenta em sua matriz curricular quatro Oficinas de Práticas Pedagógicas: OPP I, OPP II, OPP III e OPP IV com uma carga horária de $68 \mathrm{~h}$ cada. Nessas disciplinas, uma das principais atividades propostas é que os discentes elaborem uma série de aulas com os conteúdos de cada 
oficina (química geral, química analítica, química orgânica e físico-química) que serão ministradas aos colegas. Em uma segunda série de aulas, os licenciandos utilizam materiais didáticos desenvolvidos por eles, individualmente ou em grupo, para complementar o ensino daquele conteúdo. Com o objetivo de conhecer o quanto é importante para os estudantes a experiência em planejar e construir jogos didáticos para o ensino de Química durante as Oficinas de Práticas Pedagógicas foi realizado este estudo no segundo semestre de 2020 com os estudantes do oitavo, sexto e quarto semestre; primeiras turmas do curso. Foi desenvolvido um questionário no Google Formulários online que foi disponibilizado aos participantes da pesquisa através de um link enviado pelo WhatsApp. O questionário continha quatro perguntas de caracterização pessoal (faixa etária, motivo para ingressar no curso de Licenciatura em Química, se já possui licenciatura e/ou atua na área docente e em qual área, e se pretende dar aulas de Química quando terminar o curso).

Em continuidade, foi pedido aos participantes que, considerando o desenvolvimento de jogos didáticos nas Oficinas de Práticas Pedagógicas do curso de Licenciatura em Química, assinalassem uma de cinco opções em uma escala Likert de "Não concordo" a "Concordo totalmente" para cada uma das seguintes afirmativas:

- Planejar e construir os jogos didáticos mostrou-se uma tarefa fácil para você;

- É necessário ter um bom embasamento teórico e metodológico para desenvolver estas estratégias de ensino em sala de aula;

- A escolha e desenvolvimento de um jogo didático precisam ter objetivos bem definidos que promovam a construção e aperfeiçoamento de conceitos, temas e habilidades;

- Ao elaborar um jogo didático é difícil equilibrar as funções lúdica e educativa, de maneira a usá-lo de forma correta;

- Promove a articulação entre conhecimento de conteúdo e conhecimento pedagógico;

- Permite a avaliação dos próprios jogos, através de sugestões por parte de professores e colegas, de como aprimorar os jogos desenvolvidos e a auto avaliação do seu desempenho na construção dos mesmos;

- Possibilita o desenvolvimento do seu senso crítico e da sua criatividade;

- Contribui para desenvolver habilidades e competências da prática docente;

- Os jogos didáticos são capazes de proporcionar a interação e integração dos estudantes, tornando o processo de construção do conhecimento mais prazeroso e significativo; 
- Os jogos didáticos estimulam o raciocínio e favorecem a construção de conhecimentos científicos;

- Você usaria os jogos didáticos desenvolvidos para dar aula;

- Estimula você a querer ser professor(a).

A última pergunta do questionário (aberta) indagava ao participante se ele considerava que o desenvolvimento de jogos didáticos para o ensino de Química durante as Oficinas de Práticas Pedagógicas contribuiu para o fortalecimento da sua prática docente e, então, pedia para justificar a resposta. Assim sendo, o questionário foi aplicado a estudantes do curso de Licenciatura em Química que tenham cursado ao menos duas das Oficinas de Práticas Pedagógicas, nas quais desenvolveram jogos didáticos. O questionário foi respondido por 28 discentes dentre os 47 aos quais o questionário foi enviado. Desta forma, os resultados analisados correspondem às opiniões dessa amostra de estudantes. Esses resultados foram avaliados através de uma análise qualitativa e descritiva.

Segundo Bogdan e Biklen (1982), conforme citado por Lüdke e André (2015), a pesquisa qualitativa envolve a obtenção de dados descritivos, obtidos no contato direto do pesquisador com a situação estudada, enfatiza mais o processo do que o produto e se preocupa em retratar a perspectiva dos participantes. Deste modo, a pesquisa visava conhecer as percepções e os interesses dos licenciandos em relação ao desenvolvimento de jogos didáticos para o ensino de Química durante o curso e sua contribuição para a aprendizagem profissional da docência.

\section{ReSUltados E DISCUSSÕES}

A formação profissional não cessa nunca e requer a contínua aquisição de conhecimentos, atitudes e competências ao longo da carreira. Segundo a teoria da aprendizagem experiencial de Kolb, o homem é um ser integrado ao meio natural e cultural, apto a aprender a partir de sua experiência; da reflexão consciente sobre a mesma. Pelos caminhos da ação e reflexão que o ser humano transforma a si e o seu ambiente social e cultural. Todo desenvolvimento profissional decorre da aprendizagem atual, assim como o desenvolvimento já constituído é fundamental para o aprendizado. A experiência de aprendizagem é essencial para o desenvolvimento porque visa um propósito específico de aprendizado (PIMENTEL, 2007).

A reflexão e a ação são inseparáveis na educação, assim como nas outras áreas. A unidade entre reflexão e ação permitirá que o verdadeiro educador não confunda os meios com 
os fins, nem se deixe escravizar pelas técnicas que são meros instrumentos. Assim sendo, o trabalho do professor deve seguir o caminho da reflexão-ação-reflexão (HAYDT, 1995). É necessária a diversificação dos modelos e das práticas de formação dos professores estabelecendo novas relações com o saber pedagógico e científico passando pela experimentação, inovação e novas formas de trabalho pedagógico. Além disso, a formação passa por uma reflexão crítica sobre a sua utilização e por processos de investigação articulados com as práticas educativas (NÓVOA, 1992).

Nas disciplinas de Oficinas de Práticas Pedagógicas almeja-se que o licenciando aprenda a combinar os conteúdos específicos da Química à prática pedagógica, de forma inovadora, desde o segundo semestre do curso. O desenvolvimento de jogos didáticos é trabalhado nessas oficinas como uma das possíveis estratégias para a construção de saberes preparando o licenciando para a vida profissional. Assim sendo, o questionário desenvolvido foi aplicado aos participantes da pesquisa para verificar suas opiniões quanto a importância do desenvolvimento de jogos didáticos nas Oficinas de Práticas Pedagógicas do curso de Licenciatura em Química e sua contribuição para a prática docente. As respostas obtidas foram avaliadas através de uma análise qualitativa descritiva relacionando os resultados obtidos com aqueles já existentes na literatura.

Inicialmente foram feitas perguntas para caracterização dos estudantes pelas quais verificou-se que $50 \%$ deles têm entre 19 e 28 anos, $35,7 \%$ têm entre 29 e 38 anos, 10,7\% entre 39 e 48 anos e 3,6\% entre 49 e 58 anos (Figura 1).

Figura 1 - Gráfico referente à faixa etária dos estudantes

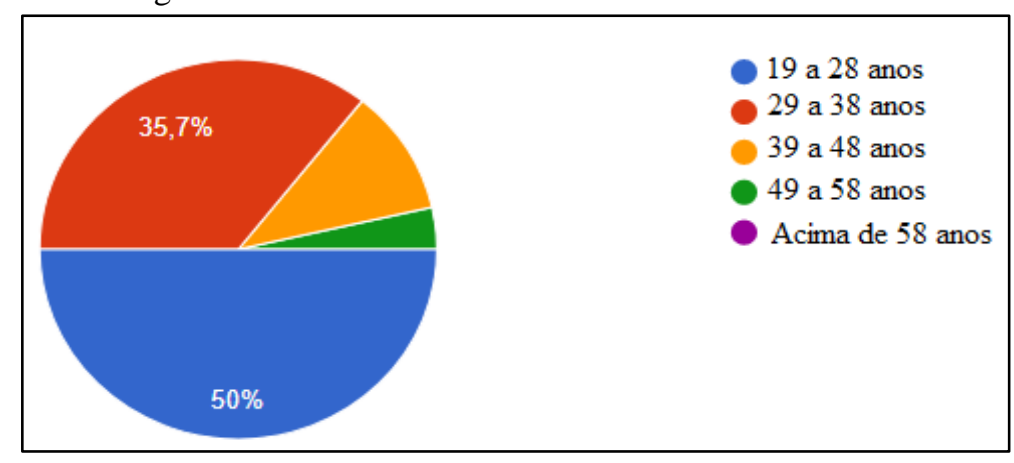

Fonte: Dados coletados na pesquisa realizada.

Sobre o motivo que levou os estudantes a ingressarem na Licenciatura em Química, a maioria (18 estudantes) respondeu qualificação para o mercado de trabalho. Em seguida, foi o aumento de oportunidade de emprego (12 estudantes), o item realização pessoal foi selecionado por 11 estudantes e 6 deles responderam que o motivo foi outro (Figura 2). Nesta questão, os 
estudantes podiam escolher mais de uma opção. A maioria dos estudantes respondeu que não possuem nenhuma Licenciatura e não atuam na área docente, mas entre os respondentes está um estudante formado em Matemática e três formados em Pedagogia.

Figura 2 - Gráfico correspondente ao motivo que levou os estudantes a ingressarem na Licenciatura em Química

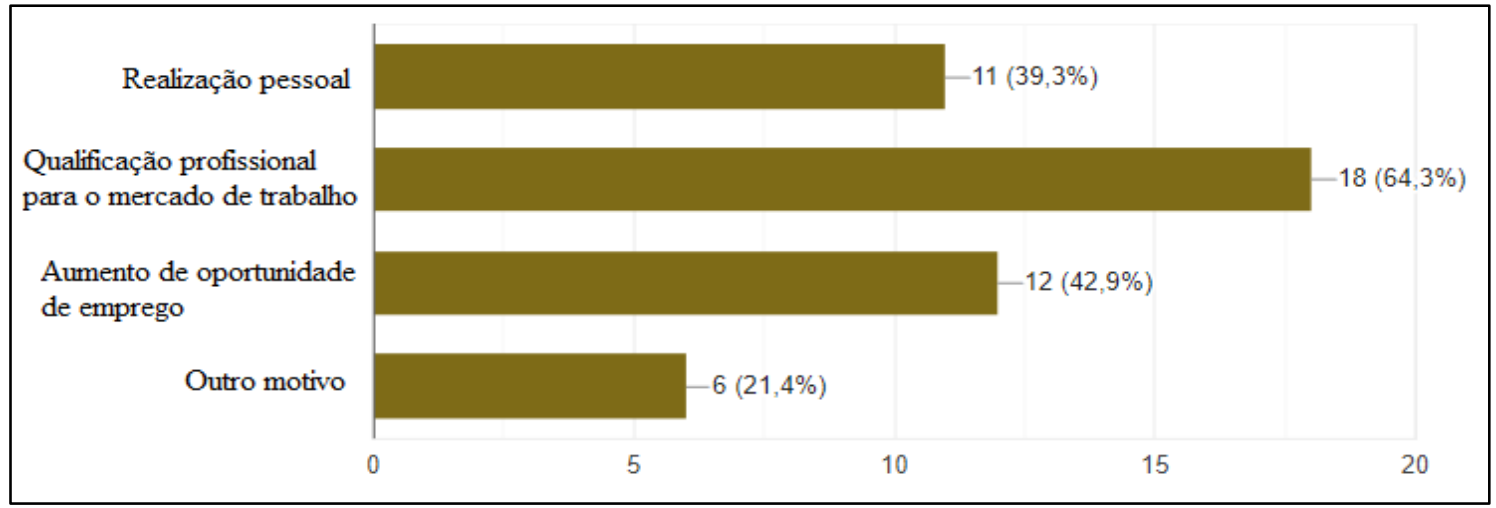

Fonte: Dados coletados na pesquisa realizada.

Finalizando esta etapa das perguntas, foi questionado se, após terminar o curso de Licenciatura em Química, o estudante pretende atuar na área. Dentre as três opções de escolha ( $\operatorname{sim}$, não e talvez) houve 14 estudantes que responderam que talvez atuem como professor de Química. A resposta sim foi selecionada por 13 estudantes e apenas 1 dos respondentes selecionou a resposta não (Figura 3). Aqui podemos visualizar que metade dos respondentes ainda não estão seguros e motivados para seguir a carreira docente. Esse resultado é semelhante ao apresentado em outras pesquisas sobre as perspectivas em relação à docência como a que é mostrada por Reis et al. (2013).

Figura 3 - Gráfico respectivo à pretensão dos estudantes em dar aulas de Química após terminar o curso

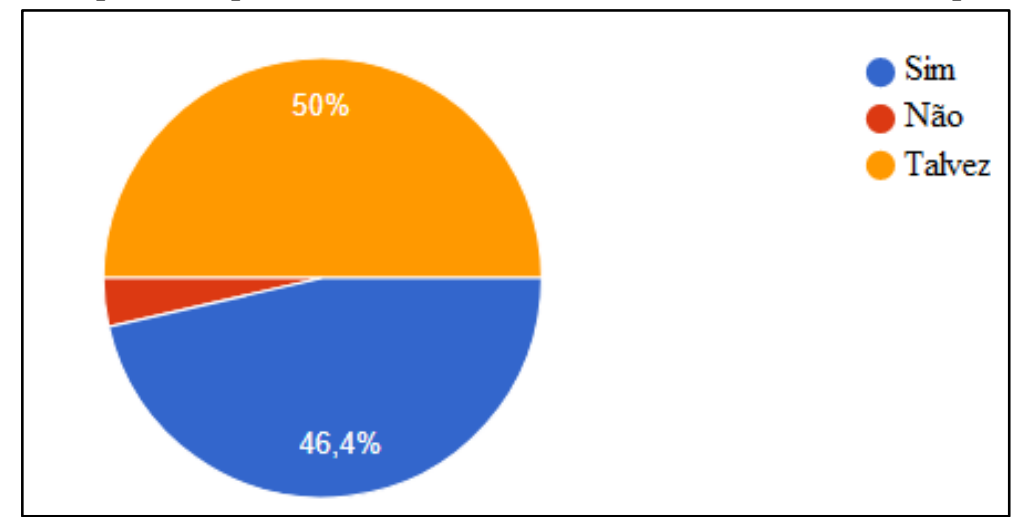

Fonte: Dados coletados na pesquisa realizada

A segunda etapa foi aquela na qual as questões foram construídas na escala Likert a qual permite verificar diferentes níveis de intensidade de opinião a respeito de um mesmo assunto. A escala continha afirmações nas quais os respondentes selecionavam uma de cinco opções em 
uma escala de "Não concordo - 1" a "Concordo totalmente - 5" considerando o desenvolvimento dos jogos didáticos nas Oficinas de Práticas Pedagógicas e sua importância na formação docente.

De acordo com Kishimoto (1996) a utilização de jogos potencializa a exploração e a construção do conhecimento, por servir-se da motivação do lúdico, fazendo com que o estudante se motive a aprender conceitos científicos. Desta forma, o lúdico é fundamental na aprendizagem, pois através desta prática o estudante tem a percepção de si mesmo como parte integrante no processo de construção de sua aprendizagem, possibilitando uma construção significativa. Nesse processo, o estudante vivencia regras, interação social, responsabilidade e desenvolve o senso crítico, a atenção, percepção e raciocínio (PINTO; TAVARES, 2010).

Nesse contexto, foram apresentadas duas afirmativas aos licenciandos para conhecer suas opiniões dentro de sua própria experiência como alunos participantes das aulas com jogos planejadas por eles mesmos ou por seus colegas. Na primeira, que os jogos didáticos são capazes de proporcionar a interação e integração dos estudantes, tornando o processo de construção do conhecimento mais prazeroso e significativo. Dentre os respondentes, $75 \%$ concordaram totalmente, houve $17,9 \%$ dos respondentes que selecionaram o nível 4 e 7,1\% o nível 3 de concordância. Na segunda afirmativa, que os jogos didáticos estimulam o raciocínio e favorecem a construção de conhecimentos científicos, 67,9\% dos estudantes concordaram totalmente e $32,1 \%$ selecionaram o nível 4 de concordância.

Para averiguar a opinião dos estudantes sobre se planejar e construir os jogos didáticos mostrou-se uma tarefa fácil, construiu-se um histograma com a frequência das respostas (Figura 4). A intensidade das respostas variou entre os cinco níveis, contudo não houve muitas respostas mostrando baixa concordância com a afirmativa. Quando é feita a proposta de planejar e construir um jogo didático, inicialmente alguns estudantes ficam inseguros, pois, geralmente, não fizeram esse tipo de atividade anteriormente. Além disso, é necessário conhecimento sobre o conteúdo de Química que vai ser abordado e conhecimento pedagógico, é preciso estudar, planejar, construir e testar o jogo. 
Figura 4 - Gráfico referente à facilidade em planejar e construir jogos didáticos

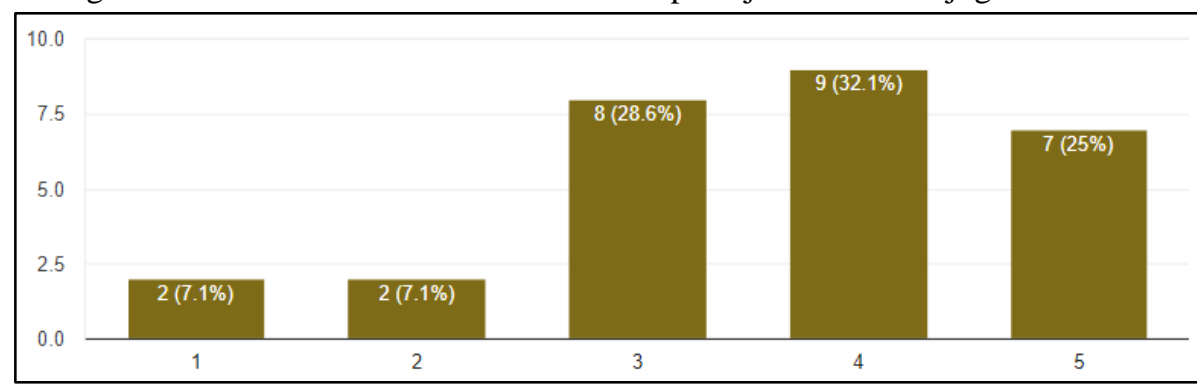

Fonte: Dados coletados na pesquisa realizada

A literatura nos mostra também que é importante haver um equilíbrio entre as atividades lúdica e educativa quando se desenvolve um jogo didático, o qual está relacionado ao ensino de conceitos e/ou conteúdos e organizados com regras, considerando os aspectos motivacional e de coerência (CUNHA, 2012). Neste sentido, foi apresentada aos estudantes a afirmativa: ao elaborar um jogo didático é difícil equilibrar as funções lúdica e educativa, de maneira a usá-lo de forma correta. A análise das respostas nos mostra que os respondentes não acharam fácil equilibrar estas duas funções em seus jogos, pois, 57,1\% concordaram totalmente com a afirmativa, 21,4\% assinalaram o nível 4 de concordância e 21,4\% o nível 3.

De acordo com o questionário aplicado, observou-se que na afirmação se é necessário ter um bom embasamento teórico e metodológico para desenvolver estas estratégias de ensino em sala de aula, a maioria $(82,1 \%)$ concordou totalmente. Somente quatro estudantes $(14,3 \%)$ assinalaram o valor 4 e um estudante $(3,6 \%)$ assinalou o valor 3 de concordância. Esse resultado mostra que a maior parte dos estudantes compreendeu que o conhecimento teórico de conteúdos químicos e também pedagógicos obtidos no processo de formação são fundamentais para o sucesso da proposta de ensino através de jogos didáticos.

Da mesma forma, quanto ao jogo ter objetivos bem definidos que promovam a construção e aperfeiçoamento de conceitos, temas e habilidades, concordaram totalmente $(82,1 \%)$ e o restante dos respondentes assinalaram o nível 4 de concordância. Cunha (2012) nos lembra que para o nível médio de ensino é recomendado jogos que apresentem regras e objetivos bem definidos que estimulam habilidades cognitivas facilitando a interiorização de conteúdos. A definição dos objetivos que se quer atingir constitui um recurso útil como elemento orientador das atividades do professor para escolher o melhor método de ensino, para saber preparar atividades capazes de gerar uma aprendizagem efetiva (SOUZA, 2015).

Nesta perspectiva, fazer uma autoavaliação do jogo desenvolvido juntamente com a avaliação por parte dos colegas e professores é importante para a correção de possíveis falhas 
e aprimoramento do material didático, de forma que possa atender ao objetivo para o qual foi desenvolvido. Quanto a avaliação dos jogos didáticos, foi feita a seguinte afirmativa: permite a avaliação dos próprios jogos, através de sugestões por parte de professores e colegas, de como aprimorar os jogos desenvolvidos e a autoavaliação do seu desempenho na construção dos mesmos. Nas respostas dos estudantes percebe-se que a avaliação dos jogos foi realizada durante as Oficinas de Práticas Pedagógicas, sendo que 71,4 \% dos estudantes concordaram totalmente com a afirmativa, 17,9 \% assinalaram o nível 4 de concordância e 10,7\% selecionaram o nível 3 de concordância.

Uma das preocupações com a formação do profissional reflexivo nos cursos de Licenciatura em Química é a falta de articulação entre teoria e prática. O contato com a prática docente deve aparecer desde o início do curso de formação de forma concomitante e articulada (PEREIRA, 1999). O planejamento de aulas a partir de jogos didáticos e sua aplicação para os colegas de curso pode ser a primeira oportunidade para os licenciandos aprenderem a articular conhecimentos específicos da Química com conhecimentos pedagógicos. Assim sendo, para conhecer a opinião dos respondentes a afirmativa foi: promove a articulação entre conhecimento de conteúdo e conhecimento pedagógico. A resposta totalmente concordante foi de 78,6\% dos respondentes, $14,3 \%$ assinalaram o nível 4 de concordância e 7,1\% o nível 3 de concordância.

Além disso, a construção de jogos também produz a habilidade de transformar o conhecimento do conteúdo de maneira que seja pedagogicamente eficaz e possível de adaptação conforme as habilidades e contextos apresentados pelos alunos na sala de aula. Ao utilizar uma metodologia de ensino com jogos didáticos, os futuros professores são estimulados a pesquisar, organizar e contextualizar conhecimentos específicos, exercitando a criatividade e o senso crítico. Esta prática pedagógica oferece aos licenciandos tanto a experiência docente de mediação do conhecimento, quanto a vivência lúdica do processo de ensino e aprendizagem de maneira a despertar o interesse dos futuros professores a reproduzir essas experiências em suas práticas docentes (LEGEY et al., 2012).

Nesse âmbito, a afirmativa colocada para os respondentes foi: possibilita o desenvolvimento do seu senso crítico e da sua criatividade. Nas respostas vemos que 78,6\% dos respondentes concordaram totalmente com a afirmativa, 10,7\% selecionaram o nível 4 de concordância e os restantes $10,7 \%$ escolheram o nível 3. A criatividade e o senso crítico devem ser inerentes à atividade proposta. No entanto, é possível que estas não se sobressaiam tanto 
quando são realizados trabalhos em grupo nos quais um ou mais participantes não colaboram de forma significante, por uma ou outra razão.

O professor deve estar atento às mudanças e acompanhá-las, buscando novas atitudes, habilidades, inovação e práticas em sala de aula. A competência do professor está na capacidade de superação, apresentando habilidades no uso de novas ferramentas didáticas de modo a proporcionar o ensino à nova geração de discentes (FERREIRA et al., 2011). Assim, foi colocada a seguinte afirmação no questionário: contribui para desenvolver habilidades e competências da prática docente. A grande maioria dos estudantes (75\%) assinalou concordo totalmente com essa afirmativa. O nível 4 de concordância foi selecionado por $21,4 \%$ dos respondentes e 3,6\% o nível 3 .

Durante as Oficinas de Práticas Pedagógicas no curso de licenciatura, esses estudantes aprendem a desenvolver jogos e a planejar aulas utilizando os mesmos. Assim, foi verificado através do questionário se eles utilizariam os jogos didáticos desenvolvidos para dar aula. A maior parte $(89,3 \%)$ dos estudantes concordou totalmente, $7,1 \%$ assinalaram o nível 4 de concordância e 3,6\% o nível 3 de concordância. Para finalizar as perguntas fechadas, foi averiguado se essas atividades estimulam os licenciandos a querer ser professor(a). Nas respostas, todos os níveis de concordância foram selecionados (Figura 5). No entanto, houve um predomínio por parte dos estudantes que concordaram totalmente com a afirmativa $(64,3 \%)$.

Figura 5 - Nível de concordância com a afirmação: estimula você a querer ser professor(a)

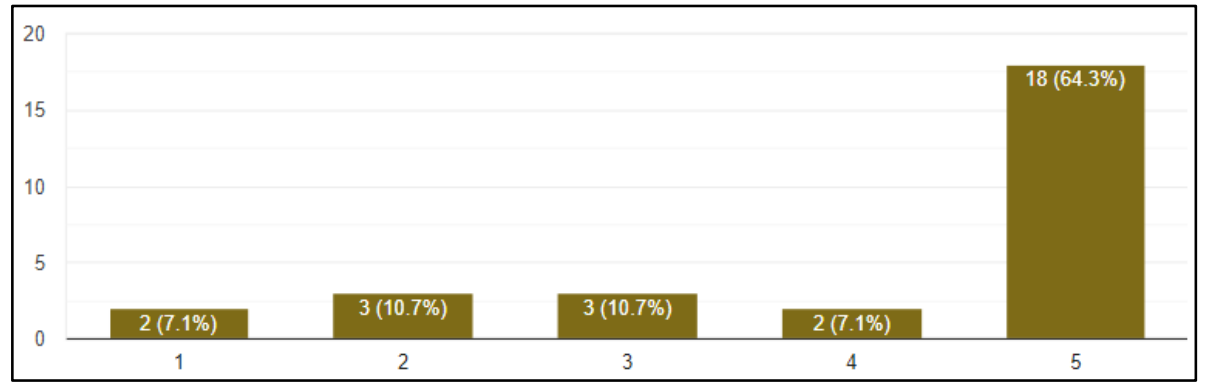

Fonte: Dados coletados na pesquisa realizada

O questionário foi finalizado com uma pergunta aberta: Você considera que o desenvolvimento de jogos didáticos para o ensino de Química durante as Oficinas de Práticas Pedagógicas contribuiu para o fortalecimento da sua prática docente? Justifique. Essa pergunta foi colocada de forma aberta para que os estudantes pudessem expressar livremente sua opinião sobre esta estratégia de ensino, da maneira a qual foi experienciada nas Oficinas de Práticas Pedagógicas, se contribuíram para a sua prática docente. Lembramos aqui, que um dos objetivos destas atividades nessas disciplinas, é desenvolver a prática docente desde os primeiros 
semestres do curso de licenciatura em uma confluência dos conhecimentos de Química com os conhecimentos pedagógicos que vão sendo aprendidos no decorrer do curso.

Ao verificar as respostas no questionário, constatamos que a maioria dos licenciandos respondeu que sim, o desenvolvimento dos jogos didáticos contribuiu para a sua prática docente; cinco estudantes responderam somente com a afirmativa sem colocar uma justificativa (Estudantes 1, 3, 5, 8 e 21) e um único estudante respondeu "depende" (Estudante 7), mas não justificou sua resposta. Apesar de terem percebido a importância do desenvolvimento dos jogos didáticos, esses estudantes podem não ter conseguido externalizar argumentos que justificassem suas respostas. Entre as justificativas apresentadas pelos estudantes respondentes estão as seguintes: "pois é necessário pesquisar, planejar e estudar dobrado para construir um objeto de aprendizagem e isso fortalece e dá mais segurança de praticar a docência!" (Estudante 4); "pois trabalhou minha criatividade e melhorou meu embasamento teórico e metodológico" (Estudante 17); " exige conhecimento pesquisa dedicação e tudo que nos agrega conhecimento é válido, ainda mais quando se trata de docência" (Estudante 15).

Essas justificativas demonstram que nas Oficinas de Práticas Pedagógicas os licenciandos vão desenvolvendo um saber experiencial com atitudes reflexivas sobre a importância do planejamento do jogo didático e dos estudos do conteúdo teórico associado a prática pedagógica. Nestas experiências, muitos estudantes se surpreendem com sua própria criatividade e capacidade e, após o esforço para realizar um bom trabalho, se sentem mais seguros em relação à prática docente.

Alguns dos respondentes justificaram no sentido de que essas atividades facilitam o aprendizado, especialmente em relação a conteúdos considerados mais difíceis. Entre elas estão as seguintes: "usar metodologias que sejam significativa e que promova a interação entre educandos e educadores para facilitar o processo de ensino" (Estudante 19); "por perceber que a aula preparada com um jogo didático facilita a compreensão do conteúdo" (Estudante 25); "pois facilita o ensino aprendizagem do aluno e posteriormente estimula a participação do mesmo" (Estudante 6); "pois eu vi que através dos jogos foi possível os alunos compreender conceitos de difícil entendimento com facilidade" (Estudante 23); "além de facilitar o entendimento do conteúdo as aulas ficam mais dinâmica" (Estudante 2); "eu pude interagir com o conteúdo, facilitando a aprendizagem" (Estudante 24).

Nestas justificativas podemos perceber como o desenvolvimento dos jogos didáticos pode contribuir para a construção de conhecimentos. Os licenciandos, ao participarem dessas 
atividades, têm o privilégio de ampliar suas aprendizagens, utilizando esse recurso a seu favor para compreender melhor os conteúdos que serão ensinados aos seus futuros alunos. Além disso, os licenciandos aprendem a partir de sua própria experiência, os conhecimentos, atitudes e competências para sua formação profissional.

Outro aspecto considerado nas justificativas foi a descoberta da possibilidade de um modo de ensinar "diferente", como coloca um dos respondentes. Esses licenciandos possivelmente tiveram sua formação baseada em transmissão-assimilação de conteúdos. Estratégias de ensino diferentes podem promover diversos caminhos de aprendizagem e de forma mais agradável tanto para o aluno quanto para o professor. Nesse sentido, os jogos didáticos devem facilitar o ensino da Química motivando os alunos a aprenderem os conceitos de forma mais atraente e dinâmica. Em seguida, algumas das justificativas apresentadas: "pois os jogos didáticos fizeram com que eu pudesse perceber as diversas formas que podemos ensinar de uma forma "diferente", além de poder aprofundar mais em determinados assuntos para assim relacionar o assunto ao tema proposto" (Estudante 22); "Por que posso fazer uma aula mais leve sobre assunto que não chamam tanta a atenção dos alunos com apenas explicações" (Estudante 11). No cenário escolar atual, com os avanços na ciência, tecnologias e sociedade, se faz necessário repensar as ações pedagógicas e inovar para tornar significativo o processo de ensino e aprendizagem (LORENCINI; SILVA, 2020).

Uma das justificativas foi: "para observar a dinâmica e olhar diferentes pontos de vista" (Estudante 10). Diante de uma mesma tarefa, como a de desenvolver um jogo didático, existem diversas formas de realizá-la. É necessário acolher os pontos de vista de outras pessoas e refletir sobre eles, principalmente se aquela tarefa for realizada em grupo. Essa flexibilidade pode surpreender de forma positiva, pois, um erro pode se tornar uma aprendizagem, uma opinião pode criar ou melhorar uma ideia e o resultado final do trabalho. Ademais, a experiência de jogar permite que os licenciandos conheçam a dinâmica de diversas possibilidades de jogos os quais poderão utilizar em sua prática docente.

Apoiados nas respostas apresentadas a partir do questionário proposto, é possível afirmar que o desenvolvimento de jogos didáticos nas Oficinas de Práticas Pedagógicas é uma prática bem avaliada pela maioria dos estudantes respondentes desta pesquisa. Desta forma, acreditamos que estas atividades podem sim fazer uma diferença positiva na formação profissional do futuro professor que aprende a planejar e desenvolver aulas inovadoras unindo os conhecimentos de Química aos conhecimentos pedagógicos. Ademais, os futuros 
professores aprendem a colocar em prática a sua criatividade, refletindo e agindo de forma a buscar o ensino e aprendizagem dos seus alunos.

\section{CONSIDERAÇÕES FINAIS}

O desenvolvimento de jogos didáticos nas Oficinas de Práticas Pedagógicas se mostrou uma estratégia promissora para a formação docente dos licenciandos. Quando conduzidas de forma adequada, essas atividades podem proporcionar o desenvolvimento de habilidades e competências importantes a um professor ativo e reflexivo mostrando-se uma valiosa ferramenta pedagógica.

No sentido de promover um ensino básico favorável às diversas ferramentas pedagógicas é necessário que os formadores dos futuros profissionais da educação sejam comprometidos em despertar uma atividade docente consciente e reflexiva, que compreende a importância do constante aperfeiçoamento dentro das inovações pedagógicas. A utilização de diferentes recursos pedagógicos requer incentivo desde a formação inicial para que os futuros professores aprendam a valorizar esses recursos, como é o caso dos jogos didáticos.

O desenvolvimento de jogos didáticos nas Oficinas de Práticas Pedagógicas é muito importante para os licenciandos compreenderem a importância em aprender essas estratégias de ensino. A partir das respostas do questionário, percebeu-se que os respondentes verificaram uma melhor aprendizagem dos conceitos relacionados aos jogos desenvolvidos. Além disso, a utilização de jogos didáticos é uma ferramenta que aproxima professores e estudantes promovendo uma interação e colaboração que facilita a construção de conhecimentos.

Nesse processo os licenciandos experienciam novas aprendizagens para os desafios da sala de aula, aprendendo a pesquisar, planejar, contextualizar, refletir, aprimorando sua formação profissional em benefício do ensino e aprendizagem de seus alunos. Numa dinâmica de ação e reflexão o licenciando aprende a ser autor de sua proposta de trabalho produzindo materiais didáticos e conhecimentos ao mesmo tempo que vivenciam desde o início do curso a experiência do ensinar.

\section{REFERÊNCIAS}

ALMEIDA, Jhenyfer Caroliny, SILVA, Luciana Aparecida Siqueira, CARVALHO, Christina Vargas Miranda. Contribuições para prática pedagógica na formação inicial de professores de química. Ciclo Revista, 1(2), 2016. Disponível em:

https://www.ifgoiano.edu.br/periodicos/index.php/ciclo/article/view/278 . Acesso em: 08 out 2020. 
BRASIL. Secretaria de Educação Média e Tecnológica. Parâmetros curriculares nacionais (Ensino Médio) - Ciências da natureza, matemática e suas tecnologias. Brasília, 2000. Disponível em: http://portal.mec.gov.br/seb/arquivos/pdf/ciencian.pdf. Acesso em: 24 mar. 2020.

BRASIL, Secretaria de Educação Média e Tecnológica. PCN+ Ensino Médio: orientações educacionais complementares aos Parâmetros Curriculares Nacionais. Ciências da Natureza, Matemática e suas Tecnologias. Brasília: MEC, SEMTEC, 2002. Disponível em: http://portal.mec.gov.br/seb/arquivos/pdf/CienciasNatureza.pdf. Acesso em: 24 mar. 2020.

CUNHA, Marcia Borin Jogos no Ensino de Química: Considerações Teóricas para sua utilização em Sala de Aula. Quím. nova esc. 34, n. 2, p. 92-98, 2012. Disponível em: http://qnesc.sbq.org.br/online/qnesc34 2/07-PE-53-11.pdf. Acesso em: 20 mar. 2020.

EVARISTO, Gabriel Filipe; GUILHERME, Christian Roberto de Farias, ALMEIDA, Vitor Luiz Campese Gonçalves de. Avaliando o potencial do jogo didático "the wall chemistry game" para o ensino de cinética química. ACTIO, Curitiba, v. 5, n. 1, p. 1-17, jan./abr. 2020. Disponível em: https://periodicos.utfpr.edu.br/actio/article/view/10854. Acesso em: 02 out. 2020.

FERREIRA, Neibher Luiz, AMORIM, Sandra da Silva, OLIVEIRA, Itamar Pereira. As habilidades e competências do professor diante dos novos recursos tecnológicos. Revista Faculdade Montes Belos, v.4, n. 2, 2011.

HAYDT, Regina Célia Cazaux. Curso de didática geral. São Paulo: Ática, 1995.

JESUS, Tatielle Rocha de; CUSTÓDIO, Rennan Siqueira; COMARÚ, Michele Waltz.

Passaqui: contribuições de uma abordagem lúdica para a formação inicial de professores de química. REDEQUIM, v 2, n 2, 2016. Disponível em:

http://www.journals.ufrpe.br/index.php/REDEQUIM/article/view/1299. Acesso em: 22 out. 2020

KISHIMOTO, Tizuko Morchida. Jogo, brinquedo, brincadeira e a educação. Cortez, São Paulo, 1996.

LEGEY, Ana Paula; MOL, Antônio Carlos de Abreu; BARBOSA, Júlio Vianna;

COUTINHO, Cláudia Mara Lara Melo. Desenvolvimento de jogos didáticos educativos como ferramenta didática: um olhar voltado à formação de futuros docentes de ciências.

ALEXANDRIA Revista de Educação em Ciência e Tecnologia, v.5, n.3, p.49- 82, 2012. Disponível em: https://periodicos.ufsc.br/index.php/alexandria/article/view/37735 Acesso em: 05 nov. 2020.

LÜDKE, Menga; ANDRÉ, Marli E. D. A. Pesquisa em educação: abordagens qualitativas. $2^{a}$ edição. Rio de Janeiro: E.P.U., 2015.

MESSEDER NETO, Hélio da Silva; MORADILLO, Edilson Fortuna de. O lúdico no ensino de química: considerações a partir da psicologia histórico-cultural. Quím. nova esc. v.38, n.4, p. 360-368, 2016. Disponível em: http://qnesc.sbq.org.br/online/qnesc38 4/11-EQF-33-

15.pdf. Acesso em: 26 mar. 2020. 
MOREIRA, Marco Antônio. Aprendizagem significativa: um conceito subjacente. Aprendizagem significativa em revista. V1(3), pp. 25-46, 2011. Disponível em: https://lief.if.ufrgs.br/pub/cref/pe_Goulart/Material_de_Apoio/Referencial\%20Teorico\%20\%20Artigos/Aprendizagem\%20Significativa.pdf. Acesso em: 02 out. 2020.

NEVES, Natália Nascimento; MOURA, Larissa Pereira de; SOUZA, Hiale Yane Silva de; SOUZA, Gahelyka Aghta Pantano. Produção de material didático no ensino de química: contribuições no desenvolvimento de um ensino contextualizado e significativo. SOUTH American Journal of basic education, technical and technological v. 1, n. 1, p. 319-326, 2017. Disponível em: https://periodicos.ufac.br/index.php/SAJEBTT/article/view/1148/965. Acesso em: 27 de mar. 2020.

NÓVOA, Antônio. Formação de professores e profissão docente. Os professores e a sua formação. Lisboa: Dom Quixote, 1992. ISBN 972-20-1008-5. pp. 13-33. Disponível em: http://hdl.handle.net/10451/4758. Acesso em: 09 out 2020.

OLIVEIRA, Antônio. L. de; OLIVEIRA, José Clovis P. de; NASSER, Maria Jucione S.; CAVALCANTE, Maria da Paz. O Jogo Educativo como Recurso Interdisciplinar no Ensino de Química. Quím. nova esc. v. 40, n. 2, p. 89-96, 2018. Disponível em:

http://qnesc.sbq.org.br/online/qnesc40_2/05- RSA-82-16.pdf. Acesso em: 20 mar. 2020.

OLIVEIRA, Andréia Machado, KAMPFF, Adriana Justin Cerveira, MIRANDA, Roxane Leandra dos Santos, ROSO, Mafalda. Aprendizagem colaborativa em construção coletiva multimídia. RENOTE, v. 5, n. 1, julho, p. 1-9, [Online], 2007. Disponível em: http://www.cinted.ufrgs.br/ciclo9/artigos/8bAndreia.pdf. Acesso em: 25 de mar. 2020.

PAVIANI, Neires Maria Soldatelli; FONTANA, Niura Maria. Oficinas pedagógicas: relatos de uma experiência. Conjectura: filosofia e educação, v. 14, n. 2, 2009. Disponível em: http://www.ucs.br/etc/revistas/index.php/conjectura/article/view/16/15. Acesso em: 25 mar. 2020.

PEREIRA, Júlio Emílio Diniz. As licenciaturas e as novas políticas educacionais para a formação docente. Educação \& Sociedade, ano XX, n. 68, p. 109-125, dez., 1999. Disponível em: https://www.scielo.br/pdf/es/v20n68/a06v2068.pdf Acesso em: 09 abr. 2020.

PIMENTA, Selma Garrido, LIMA, Maria Socorro Lucena. Estágio e docência: diferentes concepções. Revista Poíesis -V 3, n 3 e 4, pp.5-24. 2006. Disponível em: https://www.revistas.ufg.br/poiesis/article/view/10542/7012 . Acesso em: 09 out. 2020.

PIMENTEL, Alessandra. A teoria da aprendizagem experiencial como alicerce de estudos sobre desenvolvimento profissional. Estudos de Psicologia 2007, 12(2), 159-168. Disponível em: https://www.scielo.br/pdf/epsic/v12n2/a08v12n2.pdf. Acesso em: 08 set. 2020.

PINHEIRO, Ricardo Silvério Gomes, SOARES, Márlon Herbert Flora Barbosa. O lúdico e a formação de professores: elaboração e confecção do jogo mega senha da química.

REDEQUIM, v 6, n 1, 2020. Disponível em: http://www.journals.ufrpe.br/index.php/REDEQUIM/article/view/2515. Acesso em: 09 out. 2020. 
PINTO, Cibele Lemes; TAVARES, Helenice Maria. O Lúdico na Aprendizagem: Aprender e Aprender. Revista da Católica, Uberlândia, v.2, n.3, p.226-235, 2010. Disponível em: https://docplayer.com.br/6255709-O-ludico-na-aprendizagem-apreender-e-aprender-1.html . Acesso em: 27 out. 2020.

REIS, Jheniffer Micheline Cortez dos; OLIVEIRA, Brenno Ralf Maciel; KIOURANIS, Neide Maria Michellan. Perspectivas em relação à docência na formação inicial de licenciatura em química de uma universidade pública. Atas do IX Encontro Nacional de Pesquisa em Educação em Ciências - IX ENPEC Águas de Lindóia, SP - 10 a 14 de novembro de 2013. Disponível em: http://abrapecnet.org.br/atas_enpec/ixenpec/atas/resumos/R1097-1.pdf. Acesso em: 24 out. 2020.

ROCHA, Maria de Fátima; LIMA, Irielson Carneiro de; VICTOR, Camila Mayara Bezerra; SANTANA, Iany Silva de; SILVA, Luana Priscila da. Jogos didáticos no ensino de química. Formação de Professores: interação Universidade - Escola no PIBID/UFRN. Natal: EDUFRN, 2011.

SILVA, Diogo da; LORENCINI JÚNIOR, Álvaro. O docente e sua constante reconstrução de saberes: o jogo como ferramenta de ressignificação de sua prática. Revista Prática Docente. v. 5, n.1, p. 289-305, jan/abr 2020. Disponível em:

http://periodicos.cfs.ifmt.edu.br/periodicos/index.php/rpd/article/view/608/271. Acesso em: 13 nov. 2020.

SOARES, Márlon Herbert Flora Barbosa. Jogos e atividades lúdicas no ensino de química: uma discussão teórica necessária para novos avanços. REDEQUIM. v 2, n 2, 2016. Disponível em: http://www.journals.ufrpe.br/index.php/REDEQUIM/article/view/1311. Acesso em: 13 nov. 2020.

SOUZA, Jorge R. Trindade. Prática pedagógica em química. Oficinas pedagógicas para o ensino de química. $1^{\text {a }}$ edição. Belém: Editaedi, 2015.

VIEIRA, Bruna M., CRUZ, Hernani M., PIRES, Fabiana L. B., BUT, Sahmara M., HEINSCH, Zenaide. Uno Químico: um jogo de cartas criado com materiais alternativo para o ensino de Química. I Encontro Nacional de Jogos e Atividades Lúdicas em Ensino de Química - I JALEQUIM. Goiânia, GO - 29 a 31 de Janeiro de 2014. Disponível em: https://files.cercomp.ufg.br/weby/up/405/o/LIVRO DE RESUMOS.pdf. Acesso em: 08 out 2020. 